\title{
El cuerpo en la evolución de la escritura de la danza contemporánea
}

María Paz Brozas Polo*

\begin{abstract}
Resumen: En este trabajo nos interrogamos sobre las formas y los límites de la expansión de la noción de cuerpo en la danza escénica occidental de las últimas décadas. Se aborda la transformación de la escritura en la danza contemporánea a través de la identificación y confrontación de cuatro aspectos complementarios: la filosofía del cuerpo en la teoría y en la práctica coreográficas, las técnicas de conciencia corporal en los procesos de formación y composición, el diálogo de la danza con otras artes y el debate epistemológico entre el cuerpo y el movimiento como objeto/s de la danza.
\end{abstract}

Palabras clave: Cuerpo. Danza contemporánea. Evolución. Coreografía.

\section{INTRODUCCIÓN}

El término de danza contemporánea alude tanto a la danza actual como a la danza escénica que surgió, a principios del siglo XX, como alternativa a la danza clásica. En este último sentido, comprende tanto la danza moderna, conformada en las primeras décadas, como la danza posmoderna de los años sesenta y setenta y la denominada nueva danza, desarrollada a partir de los ochenta (BANES, 2002; FRIMAT, 2010; MARTIN, 2011; MORAZA, 2003; NOISSETTE, 2005; SUQUET, 2006). 
Desde los mismos inicios de la danza moderna, el cuerpo empezó a cobrar protagonismo en tanto que tema, medio y objeto de reflexión, bajo la influencia de las vanguardias artísticas, de la emergencia del cuerpo en la teoría social y, asimismo, de la aparición de nuevas prácticas corporales (BERNARD, 1980; BROZAS, 2001). Sin embargo, la presencia fehaciente del cuerpo en la escritura de la danza sólo se hace patente a partir de los planteamientos de la danza posmoderna americana. Entendiendo por escritura de la danza tanto los discursos y reflexiones como las técnicas de formación, de experimentación y de creación -los procesos y productos coreográficos-, este trabajo se conforma como una interrogación sobre los modos de concepción del cuerpo en la teoría de la danza contemporánea $\mathrm{y}$, de forma concomitante, en sus procesos de composición.

Las respuestas a dicho interrogante se acometen genealógica y dialécticamente confrontando cuatro líneas de análisis complementarias: en primer lugar, la filtración del impulso teórico sobre el cuerpo en la teoría y en la práctica de la danza; en segundo lugar, la apropiación por la danza de técnicas somáticas que modifican el entrenamiento del bailarín y, en consecuencia, la escritura coreográfica; en tercer lugar, en el terreno del diálogo de la danza con otras artes, subrayamos las contaminaciones estéticas que se articulan en torno a la presencia y la definición del cuerpo y, por último, identificamos un significativo y paradójico debate entre el cuerpo y el movimiento como objetos de la danza.

El objetivo es discernir los momentos y dispositivos que contribuyen a definir las relaciones teórico/prácticas entre el cuerpo y la danza y, eventualmente, a partir de ello, identificar lo que desde nuestro punto de vista se configura como un paradigma coreográfico.

\section{LA FILOSOFÍA DEL CUERPO EN LA DANZA}

La creciente reflexión filosófica sobre el cuerpo ha consolidado la extensión de sus límites ontológicos. Al superar viejos dualismos y otras formas del desprecio, el cuerpo se sitúa en un lugar estratégico 
de la crítica política y sociológica, ética y estética (BROZAS, 2010, p.18). No es fácil esclarecer en qué medida el cuerpo ha ido ocupando terreno en la danza pues entre ambos se da una suerte de retroalimentación: la filosofía del cuerpo incorpora la danza y la visibiliza en sus producciones a la vez que esta se apropia, en su teoría y en su praxis, de un desarrollo discursivo sobre el cuerpo no necesariamente dirigido a la danza.

Los pensamientos de Spinoza, Nietzsche, Bergson, Valèry, Bataille, Merleau Ponty, Derrida, Deleuze, Rancière, Pessoa y Foucault, entre otros, pueblan los estudios sobre danza y las reflexiones de muchos coreógrafos. El discurso crítico sobre la danza ha dado un salto considerable en el que nuevos autores con una amplia cultura filosófica y estética, contribuyen a una profundización del pensamiento en torno al hecho coreográfico (LOUPPE, 2007).

No extraña, asimismo, la incorporación de cuestiones de crítica social, pedagógica o de puro análisis conceptual o fenomenológico en los que cuerpo y la danza se alían como elementos visibles de la reflexión teórica y, en gran medida, de la reivindicación del cuerpo como texto en la escritura coreográfica.

En todo caso, en cada proyecto coreográfico subyace una concepción diferente sobre el cuerpo. Para Huws (2006, p.38), el cuerpo es "el sujeto de la danza" y el principal interés de su búsqueda creativa es encontrar qué es la danza implicando, de algún modo, la persona y el espacio. De esta manera, el cuestionamiento ontológico de la danza se inserta en los propios proyectos artísticos.

A este respecto, Sánchez (2006, p.9) propone una taxonomía dicotómica en torno a la "imposible definición de la danza" en la que distingue entre coreografías sin o con discurso propio, y entre producciones que elaboran discursos surgidos de la experiencia con el cuerpo respecto de las que usan el cuerpo para "vehicular" un contenido externo. Además utiliza el término de dramaturgia, que puede ser no verbal pero no puede reducirse a experiencia orgánica, para explicar la tensión entre el cuerpo y el logos; una tensión especialmente significativa en la danza contemporánea. 
Desde una perspectiva histórica, Louppe señala, como muestra de la atención temprana de la comunidad coreográfica a las teorías del cuerpo, la traducción al inglés de la obra del antropólogo Marcel Mauss por los bailarines americanos en los años setenta (LOUPPE, 2007). En dicha obra se define el afortunado término de "técnica corporal" (MAUSS, 1971, p.137-342). También a finales de los sesenta, la presencia de la bailarina Anna Halprin en el Esalen Institut, centro pionero de técnicas corporales en California, constata las primeras interacciones de la danza con prácticas de atención perceptiva al cuerpo (ROSS, 2007). Por su parte, Bernard, filósofo del cuerpo y de la danza, aborda un análisis de la creación coreográfica con especial atención a la invasión de técnicas somáticas, en particular Feldenkrais, Alexander y Body Mind Centering (BERNARD, 2001).

\section{LAS TÉCNICAS SOMÁTICAS Y /O DE CONCIENCIA CORPORAL COMO SUSTRATO COREOGRÁFICO}

Bales y Nettl-Fiol justifican la introducción de las "prácticas somáticas" en estudios y departamentos de danza de Nueva York de las últimas tres décadas, como métodos que permiten encontrar nuevos hábitos de movimiento y aumentar su eficacia; señalan cómo la coreógrafa Martha Myers, en el American Dance Festival en 1969, introdujo los métodos Feldenkrais, Alexander, BMC, Bartenieff y la Ideokinesis; inicialmente se presentaron como "terapias corporales" y, más tarde, se integraron en el entrenamiento de los bailarines. Myers define lo "somático" como una vasta mina de gran valor teórico pero, sobre todo, como un potencial experimental con múltiples ramas, entre las que destaca su aplicación a la danza (NETT-FIOL, 2008, p.90).

Constatamos que, así como las teorías filosóficas penetran los estudios de danza, también lo hacen algunas prácticas somáticas que surgen en ámbitos distintos a la práctica coreográfica, en particular en el terreno movedizo de las terapias y las técnicas de desarrollo personal. Este acercamiento de la danza a otras técnicas responde 
a la progresiva inclinación ontológica de la danza a la conciencia corporal, pero también a la apertura pedagógica de la danza a la diversidad de cuerpos y de métodos coreográficos.

El espectro técnico de la danza contemporánea es muy amplio debido a su vocación temprana de innovación y singularidad: la danza moderna inauguró una tendencia en la que cada personalidad coreográfica y pedagógica propone una nueva forma de aprender y escribir la danza. Además, en la medida en que la danza se construye como arte que busca y precisa la máxima conciencia corporal, surge la posibilidad de incorporar otras fórmulas de acercamiento al cuerpo y de comprensión del complejo material corporal. Estas fórmulas se añaden al amplio abanico de reservas técnicas propias de la danza moderna y posmoderna. El trabajo corporal del bailarín ya no se limita a clases de "técnica dancística" (MACIAS, 2009, p.70); sirven especialmente los métodos en los que el cuerpo se coloca en una especie de vacío o ausencia de movimiento desde donde, precisamente, todo movimiento puede surgir. Para Louppe, la justificación del encuentro entre danza y técnicas de conciencia corporal está en el estado de meditación que proporciona la danza e implica la larga búsqueda de un "cuerpo en devenir" frente al "cuerpo dado". Y en este devenir corporal intervienen las enseñanzas de Pilates, Ida Rolf, Feldenkrais y Alexander; sobre éste, con la inhibición de automatismos empobrecedores "se despeja una vía hacia una serena autonomía de la conciencia corporal" (LOUPPE, 2004, p.78). Con Feldekrais se potencia la concentración extrema sobre una parte del cuerpo desde la posición de tumbado (LOUPPE, 2004, p.45); posición habitual en estas prácticas que se incorpora en la técnica de danza Release con el nombre de "posición de descanso constructivo" (LEPKOFF, 1999) y denota la despreocupación por la búsqueda de la vertical permitiendo una liberación y una distensión que se trasladará a todos los planos y niveles espaciales de movimiento. Este trabajo permite que el movimiento coreográfico se despliegue a partir de la percepción del cuerpo-organismo y del micromovimiento. Es un hecho fundamental en la evolución de la escritura de la danza, que afecta tanto a los modos de intervención 
como a la concepción de cuerpo danzante en tanto que cuerpo sensibilizado o poroso, cuerpo abierto al espacio intra y extracorporal.

En este sentido, la relación de la danza con el yoga ha permitido la expansión del espacio dentro del cuerpo. De la filosofía y prácticas orientales nos llegan una danza y un cuerpo dilatados en el tiempo y en el espacio. La idea taoísta de microcosmos, de cuerpo cargado de senderos para la danza interior, conecta con la concepción coreográfica de geografía corporal que permite la exploración milimétrica del cuerpo. El cuerpo como espacio transparente y vital que se deja habitar por formas, emociones e imágenes es el paradigma de danzas de influencia oriental entre las que destaca el butoh, de origen japonés. Asimismo, el influjo de artes marciales como el aikido se produce en otras técnicas de danza posmoderna americana también muy extendidas como es el Contact Improvisation (BROZAS, 2000, p.310; CARVALHO LEITE, 2005). A esta forma de danza, Suquet (2006, p. 397) la sitúa en el tope de la noción de escritura coreográfica mientras la describe como quintaesencia de la aspiración perceptiva de la danza a lo largo de todo el siglo XX.

\section{Cuerpo y danza en los CRuces entre LAS ARTES}

En el siglo XX el cuerpo se configura como objeto central de la historia del arte enmarcando complejos cruces estéticos, que se acentúan en el siglo XXI en la medida en que el cuerpo se define como sujeto no solo de la danza, el teatro o la performance sino del arte biotecnológico e interactivo que diversifica las formas de comprensión, experimentación y relación con él. A este fenómeno lo denomina Quintas (2009, p.102) la "expansión tecnológica del cuerpo". Para Ramírez (2003, p.19), dibujar el mapa del cuerpo en el arte del siglo XXI es imposible, por la "monstruosa metástasis informativa": tan difícil resulta conocer los límites del cuerpo como identificar las fronteras entre las artes.

Danza teatro, danza conceptual, no-danza, danza performance, video-danza, danza virtual, danza contextual, danza híbrida, etc. son términos que nos remiten a una danza que busca su afirmación desde 
principios del siglo XX. La danza moderna consiguió desprenderse de la escenografía, la narrativa y hasta de la pose del ballet pero no totalmente de la música. Laban y Wigman en Europa y Graham y Humphrey en América, fueron impulsores notorios de esta energía independentista. De Laban, además del impacto de su pedagogía coreográfica experimental, destaca su sistema de notación, un referente en la historia de la danza tras los tratados inaugurados por Feuillet en 1700 (LOUPPE, 2010, p.181). Destacan asimismo las conferencias de 1933 en la New School de Nueva York donde Martin explicaba "el descubrimiento de la sustancia real de la danza que resultó ser el movimiento" (LEPECKI, 2009, p.18; MARTIN, 2011, p.131).

Así, el movimiento se convirtió en objeto casi exclusivo de la danza escénica, una delimitación epistemológica que consolidó su pretendida autonomía. Pero en este tiempo de consolidación, se renuevan los encuentros de la danza con las mismas artes que la vieron forjarse en las cortes europeas renacentistas: la música, la literatura, la escenografía y la pintura; encuentros que no han cesado de actualizarse con el paso del tiempo. Por tanto, la autonomía de la danza no ha implicado el desprendimiento de las demás artes pues el cuerpo/movimiento no ha renunciado definitivamente al uso de otros recursos escénicos. Detectamos al respecto, la coexistencia de una doble tensión en la danza: la que le impele al movimiento puro o la experimentación física y la que le acerca a otras artes y saberes.

Así, a lo largo del XX, la danza realizó intentos reiterativos de independencia rechazando, en primer lugar, el sincronismo y la estructura musical impuesta (BERNARD, 2001). Con la música, la danza mantuvo una íntima y duradera relación desde el barroco, pero la liberación conceptual de la danza propició un nuevo diálogo, más libre y creativo, que le ha permitido ahondar en la exploración del movimiento desde el cuerpo, y no solo desde la partitura, provocando así la revisión de los procesos de escritura coreográfica.

Por otro lado, la danza es una disciplina con una historia dinámica con las artes visuales (GREEN, 2005). A este respecto, advertimos potentes referentes de nuevos paradigmas coreográficos en Loie 
Fuller (1862-1928), en la danza futurista (1917-1935) o en la danza de Oskar Schlemmer en el seno de la Bauhaus (1919-1933) (BROZAS, 2001). Pero resultan determinantes los cambios de escritura que se fraguan en Estados Unidos en los años sesenta: fueron rupturas paralelas entre el minimalismo, el conceptual y la danza posmoderna las que modificaron los presupuestos del intercambio artístico creando un terreno común (MARTIN, 2009). Esta revolución del tejido interartístico impactó directamente sobre la escritura de la danza. Pensamos como Paxton (1987, p. 127-128) que la mezcla no es un proceso nuevo sino consustancial al arte, pero que es en el momento "multidisciplinar" de los sesenta cuando la mezcla se constituye como objeto de reflexión y reivindicación; cuando se radicalizan las interacciones y se conciben las yuxtaposiciones más inhabituales en las que también se inscribió a título pleno la danza. Se concretaron cambios relevantes en la composición coreográfica como el uso de principios aleatorios o la renovación del vocabulario gracias a los movimientos y estructuras extraídos de la vida cotidiana; además, el foco de esta danza posmoderna se situó en aspectos formales dejando la significación en un segundo plano y situando al cuerpo como espacio sensual de la danza. Se abrió una dirección de análisis puramente perceptivo donde se despoja de expresividad al movimiento buscando una presencia corporal que tiende a la neutralidad gestual. Esta fue la línea de investigación inaugurada por Yvonne Rainer en Trio A (BANNES, 2002; RAINER, 2006).

Por otra parte, este encuentro de la danza con las artes plásticas, compartiendo galerías y museos, permitió habitar nuevos espacios y públicos, ampliar los horizontes escénicos. Así, Pérez Royo asocia el surgimiento de nuevas formas de escritura posmoderna a la confrontación del cuerpo con espacios externos. Esta danza "extraescénica", ha desarrollado estéticas y escrituras basadas en la "espontaneidad, la exploración, la improvisación y la adaptación" (PEREZ ROYO, 2008, p.14). Tras el primer impulso de invasión de galerías, iglesias, museos o calles se produjo una vuelta de la danza al espacio teatral cargada con muchos de estos procedimientos creativos. El careo del cuerpo con los espacios arquitectónicos, con 
los espacios naturales o directamente en interacción con los cuerpos ambulantes se ha consolidado; testimonio de esta tendencia es la publicación digital, desde el 2006, de CQD, "Ciudades que danzan" como manifiesto internacional de danza contemporánea con programación en paisajes urbanos. Mientras una buena parte de la danza moderna trató de vitalizar la danza, situando al cuerpo en el centro de un espacio natural (playa, bosque, monte, etc.), la danza posmoderna consigue reorientar al cuerpo como dispositivo activador del espacio urbano.

Además del espacio y cierta objetivación del cuerpo, las artes plásticas ofrecen a la danza nuevas imágenes y elementos materiales de experimentación. Pero el juego del cuerpo con los objetos también está en el encuentro de la danza con el teatro, es decir, viene sucediendo tanto en la danza performance como en la danza teatro. En esta última, Pina Bausch, desde Café Müller (1976), bailando entre sillas y mesas, diseñó el camino más claro entre la danza expresionista y la danza contemporánea europea.

Un caso particular de interacción con los objetos surge desde las nuevas tecnologías que se aplican, no sólo funcionalmente, como herramientas escénicas o compositivas, sino que interponen su propia materialidad en confrontación práctica y teórica con la materialidad del cuerpo. El primer diálogo en torno a la imagen tecnológica del cuerpo se establece entre la danza y la fotografía: Debat (2009) propone una visión sobre la evolución de la escritura de la danza en relación con la imagen fotográfica en un análisis ontológico que parte del concepto de "cuerpo sensible" como materia común.

En el caso de la vídeo-danza, el cuerpo se sitúa entre la cámara y la pantalla, creando un espacio intermedio (BROZAS, 2006, p.73). En sus albores este arte era danza para la pantalla, pero con el desarrollo de la cámara portátil se convierte en danza para la cámara: además del enfrentamiento del cuerpo con su imagen se fragua la dialéctica del cuerpo escénico con la cámara. En este juego, cuerpo e imagen quieren coincidir y el cuerpo consigue reapropiarse de su imagen gracias al avance tecnológico de la cámara digital (MORAZA et al., 2003). 
De la investigación coreográfica con los espacios virtuales surge otra línea de desarrollo de la danza que ha venido, desde la temprana colaboración interartística entre Merce Cunningham y John Cage, enriqueciendo las fórmulas de creación que incorporan los conocimientos informático, audiovisual y matemático. Una primera aproximación a la interacción danza/música/números ya la planteó en los años treinta Schlemmer en colaboración con el director de orquesta Hermann Scherchen (SCHLEMMER, 1987). Al respecto, Quintas propone el concepto de composición adaptativa como superación de los mecanismos de improvisación y composición estructurada: en Swap los contenidos se generaron a partir de un sistema de retroactividad y se iniciaban por ecuaciones con elementos aleatorios (QUINTAS, 2009, p.115).

Esta tendencia tecnológica, contribuye a situar al cuerpo, más que al movimiento, como eje experimental de la creación coreográfica. Los dispositivos tecnológicos, según Debat (2009), permiten la desaparición del cuerpo real de la escena o, al contrario, una vuelta del movimiento por la medición de fuerzas y ritmos internos, y, por tanto, un retorno del cuerpo. En este sentido, Tercio se refiere a la consideración central del cuerpo como elemento transversal de las diferentes contribuciones y aproximaciones donde se encuentran danza y tecnologías (TERCIO, 2009).

Por su parte, Cornago (2008), sitúa al lado del cuerpo del actor, territorio real donde se cuestiona la autoría, el texto escrito como territorio simbólico de la misma. La actuación física se convierte en eje conceptual donde se articulan las distintas escrituras performativas, de texto o cuerpo y le otorga a la danza un lugar importante en la transformación escénica de estas escrituras en las que existe un escenario, un cuerpo y cercanía respecto de los espectadores: "la palabra cuerpo viene a ser el sustituto de la palabra teatro en un contexto de intensas relaciones entre géneros escénicos y visuales" (CORNAGO, 2008, p. 20). También el discurso de Frimat concede a la danza contemporánea cierta superioridad o privilegio respecto al teatro en cuanto al uso central aunque híbrido del cuerpo (FRIMAT, 2012). 
Los propios coreógrafos explican la capacidad interactiva de la danza contemporánea como algo consustancial a la propia danza, otorgándole una posible y discutible condición de superioridad dialogística: un lenguaje de experimentación continua, un arte permeable y esponjoso que permite visibilizar las influencias externas y un arte que proyecta sus tentáculos a otras artes (DASÍ et al., 2008).

\section{LA DANZA ¿ARTE DEL MOVIMIENTO O ARTE DEL CUERPO?}

Como un aspecto más de la apertura de la danza hacia otras artes, el cuerpo como tema coreográfico, presente en las vanguardias, se retoma en la danza posmoderna americana. Según Bannes (2002), en los años sesenta, la problemática del cuerpo se aborda directamente, es decir, el cuerpo se convierte en el sujeto mismo de la danza más que en el instrumento de metáforas expresivas: se exploran además de sus posibilidades motrices de forma amplia y exhaustiva, las posibilidades perceptivas, y otros aspectos como la desnudez y la sexualidad. En este periodo, el cuerpo no se opone al movimiento sino que lo abarca y lo supera. Se presta una atención casi científica a los mecanismos del cuerpo y se valora cada gesto y no solo el encadenamiento de movimientos (BANNES, 2002). Esta tendencia se ha extendido en Europa fundiéndose con otras propuestas, algunas derivadas de la danza europea expresionista: el cuerpo como tema explícito está, por ejemplo, en Sasha Waltz en su trilogía coreográfica sobre los estados del cuerpo: Körper (2000), S (2000) y noBody (2002).

Reconocemos así una dirección actual de la danza que elige al cuerpo como centro tanto de sus discursos como de sus recursos; ha cuajado cierta tendencia a hablar del cuerpo, a definirlo para justificar la propia danza o los procesos de la creación en torno al cuerpo. En la compañía Mal Pelo, se reivindica "el cuerpo con todo lo que trae, desde su manera de moverse hasta su imaginario personal y su capacidad de asociar" (MUÑOZ, 2008, p.75). Para Moraza esta imposibilidad de separar el cuerpo de su imaginario cultural 
constituye un elemento clave de la experiencia de la danza, independientemente de cómo se entienda ésta (MORAZA et al., 2003).

Pero Fratini (2008) describe la situación contemporánea como una laguna de estilo y de escritura, ingredientes para él constitutivos de la danza: con "una fe ciega en los axiomas orgánicos" la danza, al pensar que se escribe sola, "deja de escribirse del todo". Se refiere a "una danza obsesionada por el cuerpo", automatizada por el somatocentrismo y, en el caso de la Jeune danse francaise, la más somatizada en sus discursos, girada en torno al eje de la escritura. Paradójicamente al tema del cuerpo, disolvente de la escritura según Fratini, se une el de la escritura, quizás en un esfuerzo autocrítico de recuperación de la identidad coreográfica (FRATINI, 2008).

Asimismo, Mayen critica las nuevas escrituras coreográficas que abusan de intelectualismo y de promoción de la no danza: una danza que bebe de los estudios universitarios de danza donde se incorporan los referentes filosóficos y donde se produce el atrevimiento de la producción intelectual de los propios artistas. Esta no- danza se dedica a criticar el "bello gesto" y a cultivar en su lugar "el movimiento interior, la moderación tónica y el tempo ralentizado" (MAYEN, 2008, p.25). También Bernard trata de desvelar las contradicciones del discurso organicista, "los subterfugios de las pedagogías de la corporeidad", en particular, en relación con los ya mencionados métodos de Alexander y Feldenkrais, tal como los adopta e incorpora la danza (BERNARD, 2000, p.71-77).

En este punto, se pone de relieve cómo, en algunos coreógrafos contemporáneos, el cuerpo llega a ocupar el lugar preponderante que había conseguido ocupar el movimiento como objeto de la danza; el movimiento pasaría a situarse como elemento consecuente o relativo al cuerpo; es el caso de Olga Mesa, que siempre ha "entendido el cuerpo como lo básico, es decir, primero está el cuerpo, después el movimiento, la palabra, el gesto. El cuerpo es el punto de partida" (MESA, 2003, p.65). Pero reconocer al cuerpo no significa necesariamente negar o relegar el movimiento. Podría ser 
precisamente el cuerpo en movimiento el objeto de la danza (LEVIN, 2009, p.4). Por su parte, Amagatsu subraya el cuerpo como fundamento del movimiento: "el cuerpo es el soporte, el asiento mismo de la danza, antes de que ésta haya tenido lugar a hablar" (AMAGATSU, 2000, p.15). También en Fontaine el cuerpo en tanto sujeto, objeto y materia de la danza, se concibe como "una temporalidad provisional productora de otra temporalidad provisional: el movimiento" (FONTAINE, 2004, p.11).

En el Manifiesto futurista sobre la danza (1917) de Marinetti surgió un dilema entre el movimiento como emblema de la danza futurista ¿danza de la modernidad? y la aproximación posible a la danza desde las artes plásticas, que en el proceso de escritura, tienden a paralizar la danza (BROZAS; GARCÍA, 2008).

Según Lepecki (2009), el cuerpo danzante que caracteriza la modernidad es un objeto mudo ambulante, un ser puro hacia el movimiento en una danza que se escribe con este ideal de constante agitación y continua movilidad; y la reducción del movimiento en la coreografía tiende a percibirse como indicador de inactividad, como un mal augurio para la danza o una traición al vínculo danzamovimiento. Pero la lentitud y la detención pueden entenderse como actos críticos de la representación y también como una "interrogación de la ontología política de la danza" (LEPECKI, 2009, p.88) que abarca la revisión crítica del estatus del cuerpo del bailarín y también la supuesta singularidad del autor-coreógrafo. A este respecto, cuestiona no solo el movimiento sino también la subjetividad individualista propios de la modernidad. Es en la propia danza, en la coreografía como tecnología de subjetivación que fusiona la escritura con el movimiento y con el cuerpo, donde se encuentra la posibilidad de superar la concepción moderna del "ser hacia el movimiento, aislado, socialmente amputado, autopropulsado" (LEPECKI, 2009, p.77).

Finalmente, en la definición de danza de Paul Valéry encontramos el continuo dinamismo corporal de metamorfosis junto al juego de hacer y deshacer de la temporalidad, el diálogo con la 
gravedad y la pulsión autoafectiva o autoreflexiva (VALÉRY, 2011, p.89). Esta última se refiere a un deseo intenso de vuelta a la corporeidad en aparente contradicción con el proceso continuo de metamorfosis que intenta negar la unidad del cuerpo en la diversidad de sus actos (BERNARD, 2000, p.84). La conciliación sólo es posible concediendo un lugar de privilegio a la percepción corporal en la danza. La danza se convierte así en toma de conciencia del cuerpo y agudización perceptiva de las referencias que sitúan nuestro cuerpo (MARSAL, 2007, p.301). Parafraseando a Roux (2007, p.42), el movimiento bailado ya no se define según una virtuosidad codificada o según una necesidad de expresividad sino que es ante todo un estado de conciencia que adquiere sentido en la efectuación y, en ocasiones, gracias al dominio de la ampliación perceptiva, el movimiento se desarrolla en la inmovilidad aparente.

\section{Conclusiones}

A principios del siglo XX el movimiento se consagra como objeto de la danza moderna, y a finales, el cuerpo, releva y sobrepasa al movimiento al proponer su imagen así como su densidad material y cultural.

Entre los años sesenta y setenta, confluyen múltiples procesos que permiten la configuración de la danza posmoderna y la progresiva colocación del cuerpo en el centro de las teorías y/o de las prácticas coreográficas. Destacan la apertura coreográfica -perceptiva, política e interdisciplinar- inaugurada por la Judson Church, la incorporación del concepto de técnica corporal de Marcel Mauss en los estudios de danza, la introducción de las prácticas somáticas dulces en el entrenamiento del bailarín, el despliegue cultural en torno al mayo francés, así como el surgimiento de la danza-teatro de Pina Bausch.

Diversas disciplinas artísticas sitúan al cuerpo como eje temático o experimental, proponiendo lugares de referencia desde donde abordar nuevas direcciones coreográficas. El teatro le cede a la danza texto y objetos; la performance, desde las artes plásticas, imagen y acción; el cine y el vídeo, un movimiento extracorporal, y 
la informática, un cuerpo virtual. La música, por su parte, ofrece a la danza, azar y silencio. El cuerpo atraviesa con dulzura y a veces con crudeza las fronteras, siempre volátiles, entre las artes.

Se constata cierta reticencia por parte de algunos sectores de la crítica al advenimiento del cuerpo como objeto de la danza. Por un lado, se manifiesta un miedo a la pérdida de escritura, al vacío, a la quietud, al no movimiento. Pero, por otro, la continua mezcla e intercambio con otras artes, e incluso cierta indefinición de la danza, que no puede ser solo encadenamiento motor, empujan y alimentan la reflexión y la escritura coreográficas.

Centrarse en el cuerpo no aleja a la danza del movimiento, sino que puede ampliar el espectro motor de lo "coreografiable". Ha sido preciso ralentizar el cuerpo e incluso detenerlo, para explorar los pequeños o invisibles movimientos, los tropiezos, los movimientos no catalogados, los movimientos excluidos de los códigos tradicionales de las danzas. La investigación coreográfica, en tanto experiencia y pensamiento, ha introducido la lupa y el microscopio en un cuerpo que no puede dejar de ser continente de la danza. La búsqueda estética y pedagógica en torno a la conciencia corporal predomina en la danza actual, la cual sitúa al cuerpo en el centro de sus discursos, de sus recursos y de sus procedimientos creativos. 
O corpo na evolução da escrita da dança contemporânea

Resumo: Neste trabalho questionamo-nos acerca das formas e limites da expansão da noção de corpo na dança cênica ocidental das últimas décadas. Ocupamo-nos da transformação da escrita na dança contemporânea através da identificação e confronto de quatro aspectos complementares: a filosofia do corpo na teoria e na prática coreográficas; as técnicas de consciência corporal nos modos de formação e composição; o diálogo da dança com outras artes e, a controvérsia de um paradigma ontológico onde o corpo se debate com o movimento quanto objeto da dança. Palavras-chave: Corpo. Dança contemporânea. Evolução. Coreografia

The body in the evolution of the writing of
contemporary dance
Abstract: In this paper we inquire about the forms
and limits of the expansion of the notion of body in the
Western stage dance in recent decades. It deals with
the transformation of writing in contemporary dance
through the identification and comparison of four
complementary aspects: the philosophy of the body in
theory and choreographic practice, techniques of body
awareness in the modes of formation and composition,
dialogue between dance and other arts, and the
controversy of an ontological paradigm where the body
struggles with movement for being objet of the dance.
Keywords: Body. Contemporary dance. Evolution.
Choreography.

\section{REFERENCIAS}

AMAGATSU, Ushio. Dialogue avec la gravité. Arles: Actes Sud, 2000.

BALES, Melanie; NETTL-FIOL, Rebecca (Ed.). The body eclectic. Evolving

Practices in Dance Training. Urbana \& Chicago: University of Illinois, 2008. 
BANES, Sally. Terpsichore en baskets: Post-moderne dance. París: Chiron, 2002.

BERNARD, Michel. El cuerpo. Barcelona: Paidós, 1980.

BERNARD, Michel. De la création chorégraphique. Tours: Centre National de la danse, 2001.

BROZAS, Ma Paz. Contact Improvisation: danza, acrobacia y pedagogía corporal. In: I CONGRESO DE LAASOCIACIÓN ESPAÑOLADE CIENCIAS DELDEPORTE, 1. 2000. Actas.... Cáceres: Universidad de Extremadura, 2000. p. 309-316.

BROZAS, Ma Paz. Tendencias expresivas de la danza europea de principios de siglo XX. In: SIMPOSIUM HISTORIA DE LA EDUCACIÓN FÍSICA 8, 2001. Salamanca: Universidad de Salamanca, 2001. p. 97-114.

BROZAS, Mํㅡㄹ $\mathrm{Paz}$. Cuerpo e imagen en el encuentro de la danza con otras artes. In: BROZAS, Ma Paz. Cuerpo, imagen y expresión: Entre la creación artística y la intervención educativa. León: Universidad de León, 2006. p. 59-75.

BROZAS, Mํㅗㄹ Paz. La expansión del cuerpo en la escritura de la danza y el proceso "In verso". In: GARCÍA, M. E.; GÓMEZ, B. El cuerpo creado: Representaciones del cuerpo en la contemporaneidad. Alicante: Museo de la Universidad de Alicante, 2010. p. 18-27.

BROZAS, Ma Paz; GARCÍA, Eugenia. El manifiesto de la danza futurista (Marinetti 1917): distancias entre la teoría y la práctica y/o resistencias del cuerpo. In: SÁNCHEZ, G.; COTERÓN, J.; GIL, J.; SÁNCHEZ, A. EI movimiento expresivo. Salamanca: Amarú, 2008. p. 607-611.

LEITE, Fernanda Hubner de Carvalho. Contato improvisação (contact improvisation) um diálogo em danca. Movimento, Porto Alegre, v.11, n.2, p.89-110, maio/ago. 2005.

CORNAGO, Óscar. Éticas del cuerpo. Madrid: Editorial Fundamento, 2008.

COTERÓN, J.; GIL, J.; SÁNCHÉZ, A. El movimiento expresivo. Salamanca:Amarú, 2008. p. 607-611.

DASÍ, Oscar et al. Tradiciones \& traiciones, las fidelidades del cuerpo. Reflexiones en torno a la danza: Caligrafías del cuerpo. Barcelona: Mercat de les Flors, 2008. N.3. Disponible en: www.mercatflors.org. Acceso en: 12 de nov. 2010.

DEBAT, Michelle. L'impossible image: Photographie-danse-chorégraphie. Vottem: La Lettre Volée, 2009.

FONTAINE, Geisha. Les danses du temps. Pantin: Centre Nacional de la Danse, 2004. 
FRATINI, Roberto. Por una dramaturgia silenciosa. La desconfianza en los movimientos del texto. Reflexiones en torno a la danza: Caligrafías del cuerpo. Barcelona: Mercat de les Flors, 2008. N. 3, p. 19-23. Disponible en: http:// www.mercatflors.org. Acceso en: 14 de nov. 2010.

FRIMAT, Francois. Qu'est-ce que la danse contemporaine? Politiques de l'hybride. París: PUF, 2010.

GREEN, Portland. A space for dance? Dance Theater Journal, London, v. 21, n. 2, p. 8-12, 2005.

HUWS, Sioned. Choregraphic presence and the technological present. Dance Theater Journal, London, v. 21, n. 4, p. 37-41, 2006.

LEPKOFF, Daniel. What is Release Technique? Movement Research Performance Journal, New York, n. 19, fall/winter 1999. Disponible en: www.movementresearch.org. Acceso en: 20 abr. 2010.

LOUPPE, Laurence. Poétique de la danse contemporaine. Bruselas: Contredanse, 2004.

LOUPPE, Laurence. Poétique de la danse contemporaine: La suite. Bruselas: Contredanse, 2007.

LOUPPE, Laurence. Les imperfections du papier. In: ANDRIEN, Baptiste; CORIN, Florence (Ed.). De l'une à l'autre: Componer, apprendre et partager en mouvements. Bruxelles: Contredanse, 2010. p. 162-185.

MACIAS, Zulai. El poder silencioso de la experiencia corporal en la danza contemporánea. Bilbao: Artezblai, 2009.

MARSAL, Lucie. Dancité, corps et graphie. Comme une danse: Les carnets du paysage, Arles, n. 13-14, p. 301-317, hiver 2007.

MARTIN, Alberto. Reflexiones coreográficas. Art\&Co, Madrid, n. 5, p. 6-13, 2009.

MARTIN, John. La danse moderne. In: Danser sa vie: Écrits sur la danse. París: Editions du Centre Pompidu, 2011. p. 131-137.

MAYEN, Gerard. Siempre se lee un cuerpo texto. Reflexiones en torno a la danza: Caligrafías del cuerpo. Barcelona: Mercat de les Flors, 2008. n. 3, p. 25,. Disponible en: http://www.mercatflors.org. Acceso en: 13 nov. 2010.

MAUSS, Marcel. Concepto de la técnica corporal. In: Sociología y Antropología. Madrid: Tecnos, 1971. p. 337-342.

MESA, Olga. La danza empieza en la mirada. In: SANCHEZ, José A.; CONDESALAZAR, Jaime. Cuerpos sobre blanco. Cuenca: Universidad de Castilla La Mancha, 2003. p. 65-71. 
MORAZA, Juan Luis et al. Cuerpo e imagen en la nueva danza. In: SANCHEZ, José A.; CONDE-SALAZAR, Jaime. Cuerpos sobre blanco. Cuenca: Universidad de Castilla La Mancha, 2003. p. 92-102.

MUÑOZ, María. Carta blanca a la vida en danza. Reflexiones en torno a la danza. Caligrafías del cuerpo. Barcelona: Mercat de les Flors, 2008. n. 3, p. 6570. Disponible en: www.mercatflors.org. Acceso en: 12 nov. 2010.

NETTL-FIOL, Rebecca. Somatics: a current moving the river of contemporary dance. A interview with Martha Myers. In: BALES, Melanie; NETTL-FIOL, Rebecca. The body eclectic: Evolving Practices in Dance Training. Urbana \& Chicago: University of Illinois , 2008. p. 89-100.

NOISETTE, Philippe. Le corps dans la danse. París: La Martinière, 2005.

PAXTON, Steve. Improvisation is a word for something that can't keep a name. CQ Spring/Sommer. In: Contact Quaterly's Contact Improvisation Source Book: collected writings and graphics from Contact Quaterly dance journal 19751992. Northampton, Mass.: Contact Editions, 1987. p. 125-129.

PÉREZ ROYO, Victoria. Danza en contexto. Una introducción. In: PÉREZ ROYO, Victoria. ¡A bailar a la calle! Danza contemporánea, espacio público y arquitectura. Salamanca: Universidad Salamanca, 2008. p. 13-65.

QUINTAS, Rodolfo. O ciclo Swap-project: o corpo e a sua expansão tecnológica (2000-2007). In: TERCIO, Daniel. TEDANCE Perspectivas sobre dança en expansão tecnológica. Lisboa: Facultad de Motricidad Humana, 2009. p. 101117.

RAINER, Ivonne. Feelings are facts: a life. Cambridge: MIT, 2006.

RAMÍREZ, Juan Antonio. Corpus Solus: Para un mapa del cuerpo en el arte contemporáneo. Madrid: Siruela, 2003.

ROSS, Janice. Anna Halprin: Experience as dance. Berkeley: Universtity of California, 2007.

ROUX, Céline. Danse (s) performative (s). París: L'Harmattan, 2007.

SÁNCHEZ, Jose Antonio. De límites y esencias. Reflexiones en torno a la danza. En moviment. Barcelona: Mercat de les Flors, 2006. no 1, p. 9. Disponible en: http://www.mercatflors.org. Acceso en: 13 nov. 2010.

SUQUET, Annie. Escenas. El cuerpo danzante: un laboratorio de la percepción. In: Historia del cuerpo: El siglo XX. Madrid: Taurus, 2006. v. 3, p. 379-399.

SCHLEMMER, Oskar. Escritos sobre arte: pintura, teatro, danza. Barcelona: Paidós, 1987. 
TERCIO, Daniel. TEDANCE Perspectivas sobre danca en expansão tecnológica. Lisboa: Facultad de Motricidad Humana, 2009.

VALÉRY, Paul. Philosophie de la danse. In: Danse sa vie : Écrits sur la danse. París: Editions du Centre Pompidu, 2011. p. 83-94.

Endereço para correspondência:

Ma Paz Brozas Polo

FCAFD-Universidad de León

Campus de Vegazana S/N 24071, León, España

Recebido em: 21-12-2012

Aprovado em: 20-04-2013 